\title{
Effectiveness of cross-border knowledge transfer in Malaysian MSC status corporations
}

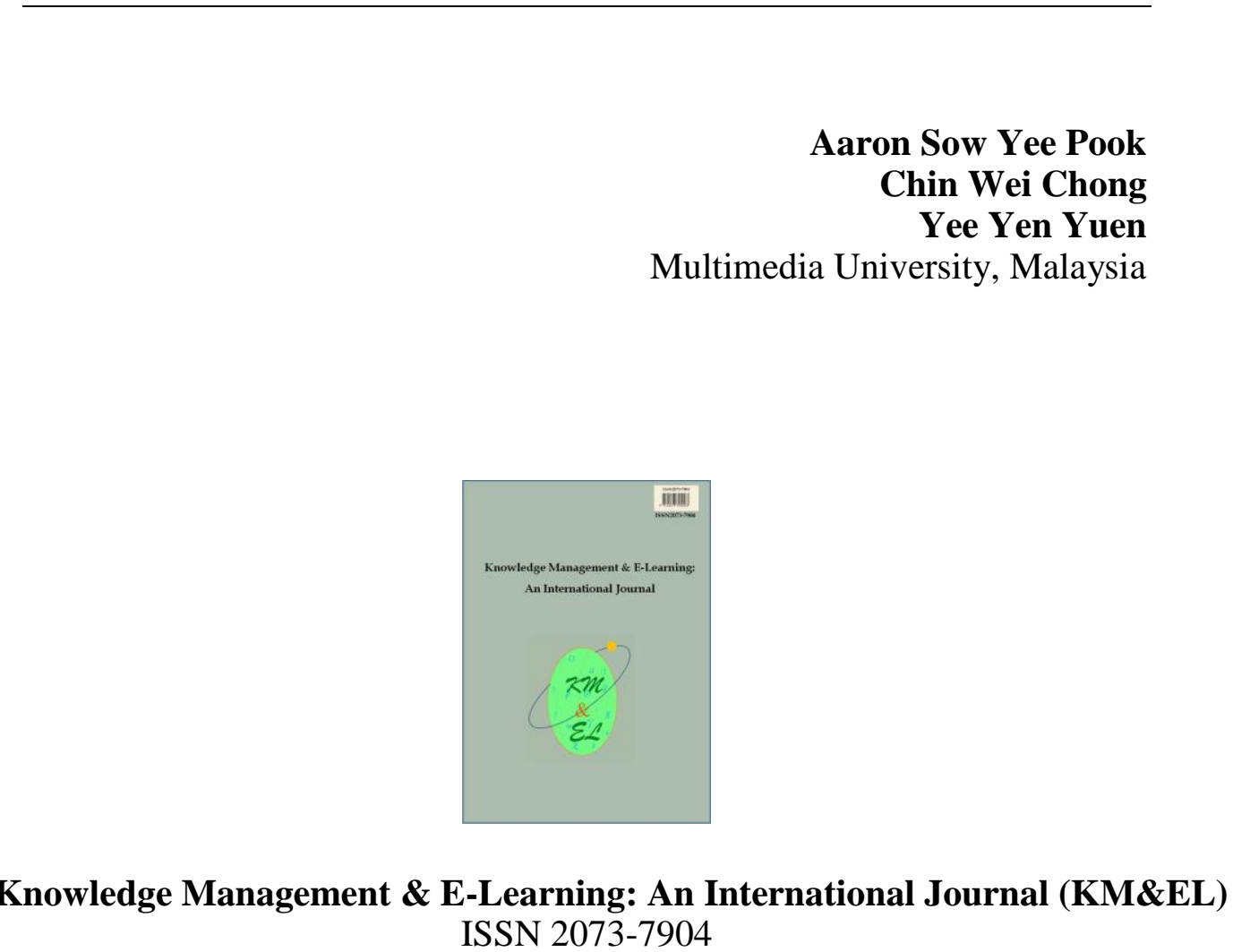

ISSN 2073-7904

Recommended citation:

Pook, A. S. Y., Chong, C. W., \& Yuen, Y. Y. (2017). Effectiveness of cross-border knowledge transfer in Malaysian MSC status corporations. Knowledge Management \& E-Learning, 9(1), 90-110. 


\title{
Effectiveness of cross-border knowledge transfer in Malaysian MSC status corporations
}

\author{
Aaron Sow Yee Pook* \\ Faculty of Business \\ Multimedia University, 75450 Melaka, Malaysia \\ E-mail: sypook@mmu.edu.my

\section{Chin Wei Chong} \\ Graduate School of Management \\ Multimedia University, 63100 Cyberjaya, Malaysia \\ E-mail: cwchong@mmu.edu.my
}

\section{Yee Yen Yuen}

Faculty of Business

Multimedia University, 75450 Melaka, Malaysia

E-mail: yyyuen@mmu.edu.my

*Corresponding author

\begin{abstract}
Knowledge has become the key asset for the economy to gain competitiveness as more and more countries have shifted or are shifting towards knowledge-based economy, no exception for Malaysia. In order to acquire and transfer technology and/or knowledge from overseas to Malaysia, Multimedia Super Corridor (MSC) has been proposed. However, research focuses on cross-border knowledge transfer especially in the context of MSC status corporations in Malaysia is still limited. The factors that affect the effectiveness of cross-border knowledge transfer will be determined and presented in this paper. Quantitative approach has been adopted in this study. The findings of this study show that knowledge characteristics (KC) and network characteristics (NC) have positive significant relationship with crossborder knowledge transfer. The effects context towards $\mathrm{KC}$ and $\mathrm{NC}$ will also be examined in this study.
\end{abstract}

Keywords: Knowledge transfer; Multimedia super corridor (MSC); Crossborder; Knowledge characteristics; Network characteristics; Knowledge context

Biographical notes: Aaron Sow Yee Pook is a lecturer, as well as the Head of Department of KMEQA (Knowledge Management, Economics \& Quantitative Analysis) in the Faculty of Business (FOB) at Multimedia University (MMU), Malaysia. His research interests include knowledge management, knowledge transfer, and information systems. Currently, he is pursuing his Ph.D. in the area of knowledge management in MMU, Malaysia.

Dr. Chin Wei Chong is a researcher in the areas of people management and soft side of knowledge management. She has published 19 papers in international refereed journals, of which 10 are indexed by Thomson ISI with 13 of them in 


\begin{abstract}
MMU Tier $1 \&$ Tier 2 journals. She was awarded as Outstanding Reviewer by Emerald Literati Network and Outstanding Researcher Award by MMU in 2011. She has also contributed and shared her experience by becoming reviewer and serve as panel in MMU's various research / grant committees. She is currently the Deputy Dean of Research and Development in Graduate School of Management (GSM).

Dr. Yee Yen Yuen is an active researcher in the areas of knowledge management and information system acceptance. His research mainly focuses on studying knowledge transfer and information system acceptance between developed and developing countries. He has formed research collaboration teams with several international research partners from renowned universities to examine the influence of cultural factors on the digital divide in developed and developing countries.
\end{abstract}

\title{
1. Introduction
}

Many countries have shifted, or are shifting, from an industrial-based economy to a knowledge-based economy. Certainly, knowledge has become the key asset for the economy to gain competitiveness. Besides that, the knowledge-based economy is also expected to promote an environment for innovation by reinforcing the delivery of better quality education and fostering innovation and technology. The pressure of competitiveness and innovation, therefore, has led to many countries (including developing countries) to set up a technology park for promoting innovation and knowledge transfer. As one of the developing countries, Malaysia launched a technology park and named Multimedia Super Corridor (MSC) as the foundation for the knowledgebased economy in the mid-1990s. The aim of MSC Malaysia developed by Malaysia Digital Economy Corporation (MDEC, see http://www.mscmalaysia.my/) is to nurture local ICT small and medium enterprises (SMEs) to become world-class businesses at the same time to attract international ICT companies to invest in Malaysia. With MSC, the local ICT SMEs can gain new knowledge by conducting research and developing new technologies together with international ICT companies, especially those from developed countries such as United States, Japan, Singapore, and etc. Knowledge that transferred from the developed countries can then be used by Malaysia in developing ICT infrastructure such as smart schools, e-government, e-business, e-healthcare, and etc.

In order to attract Foreign Direct Investment (FDI) and Domestic Direct Investment (DDI) in ICT industry, Malaysian government offers a set of incentives and privileges under the scheme of Bill of Guarantees (BoGs) such as income tax exemption, freedom to source capital globally, provide globally competitive telecommunications tariffs and etc. to the enterprises who granted the MSC status (see http://www.mscmalaysia.my/). However, in order to enjoy these incentives and privileges of the MSC status, the enterprises must fulfil the criteria such as they must be the heavy users or suppliers of multimedia products and services; to employ a huge number of knowledge workers; and to outline how the technology and/or knowledge will be transferred to Malaysia, or otherwise contribute to the development of the MSC and the Malaysian economy.

The important of knowledge transfer in promoting MSC and developing Malaysian economy has drawn the attention of local researchers to focus on the study of knowledge transfer in SMEs (Whah \& Tiek, 2013; Razak et al., 2013; Chong, Chong, \& 
Gan, 2011) and MNCs (Chen, Sandhu, \& Jain, 2009; Lee, Mohayiddin, \& Kanesan, 2011). Although there are some researchers focus on knowledge transfer in Science and Technology Parks Malaysia (Sarif \& Ismail, 2006; Awang, Hussain, \& Malek, 2009), the focus of cross-border knowledge transfer especially in the context of MSC status corporations in Malaysia is still limited. Moreover, the impacts of recipient and source of knowledge have been well discussed in many prior researches of knowledge transfer (Kumar, Rose, \& Muien, 2011; Hamid \& Salim, 2011; Zarrinmehr \& Rozan, 2012). Hence, these two characteristics will not be focused in this paper anymore. Instead, this paper will examine the influences of knowledge characteristics, knowledge context and network characteristics towards the effectiveness of cross-border knowledge transfer in the MSC status corporations in Malaysia. In the previous studies, knowledge characteristics (Simonin, 2004; Kang, Rhee, \& Kang, 2010), knowledge context (Cummings \& Teng, 2003; Jiang, Tang, Wang, \& Tang, 2010), and network characteristics (Reagans \& McEvily, 2003; Inkpen \& Tsang, 2005) have been studied individually. Therefore, this paper will be the pioneer study to examine the relationship among these three instruments by cooperating them in a framework.

With the effective cross-border knowledge transfer, knowledge and skills can be transferred in a timely manner from the international business affiliates (IBAs) to the Malaysian MSC status corporations. Also, effective international knowledge spillovers are therefore beneficial and critical to Malaysia for achieving the goal. Relevant literature of knowledge transfers as well as knowledge characteristics, knowledge context and network characteristics will be presented in the following section. Furthermore, the effects of knowledge context towards knowledge and network characteristics will also be discussed. This paper will also present the methodology for this study and report the findings of the empirical test. This paper will be ended with discussions and future research directions.

\section{Literature review}

\subsection{Effectiveness of cross-border knowledge transfer (KT)}

Knowledge transfer is one of the major strands of the area of knowledge management. It concerns with the movement of knowledge across the boundaries created by specialised knowledge domain (Carlile \& Rebentisch, 2003). According to Joshi, Sarker, and Sarker (2007), the process of knowledge transfer is to diffuse the knowledge from one entity, such as an individual, an organisation or a group to another. Furthermore, Weidenfeld, Williams, and Butler (2010) defined knowledge transfer as a process of learning that results in the creation of knowledge. Fallah and Ibrahim (2004) distinguished the difference between knowledge transfer and knowledge spill over based on the intention of exchanging knowledge. In contrast with knowledge spill over which happens beyond the intended boundary, knowledge transfer occurs only when the knowledge is being exchanged intentionally with a group of people inside the company (Fallah \& Ibrahim, 2004).

Through the knowledge transfer, organisations are able to determine which knowledge is unidentified and which knowledge is appropriate to be put into use (Ciabuschi, Martín, \& Ståhl, 2010). According to Weidenfeld et al. (2010), knowledge transfer is crucial for an organisation to achieve competitiveness. In addition, it is also essential for organisational performance and innovation (Adams \& Comber, 2013; Cavusgil, Calantone, \& Zhao, 2003; Tsai, 2001; Weidenfeld et al., 2010). Szulanski 
(1996) suggested that the characteristics of knowledge, recipient, source and context are key factors that might influence the process of knowledge transfer. Furthermore, Albino, Garavelli, and Gorgoglione (2004) also proposed a similar model with three main components, which are source, recipient and object (knowledge) exchanged, in studying technology adoption in knowledge transfer. According to Pérez-Nordtvedt, Kedia, Datta, and Rasheed (2008), the effectiveness of knowledge transfer can be measured based on four dimensions, which are comprehension, usefulness, speed and economy. In this study, the authors will focus on how knowledge can be transferred across countries as crossborder knowledge transfer is more sophisticated due to its multifaceted nature of the boundaries, cultures and processes involved. Four key factors affecting cross-border knowledge transfer, targeted by this study, are as follows.

\subsection{Knowledge characteristics $(K C)$}

The relation between data, information and knowledge is often misunderstood and this confusion can cause problems in information systems design (Tuomi, 1999). According to Godbout and Godbout (1999), data, information, and knowledge can be distinguished based on a hierarchical view. Data can be viewed as raw numbers or simple facts which have no context; information is data that are organised or structured; and knowledge is when information has been interpreted (Tuomi, 1999). In short, data can be processed and transformed into information and information can be processed and transformed to become knowledge (Gottschalk, 2004). Furthermore, knowledge can also be viewed as an intangible asset, which is different from tangible assets. Tangible assets tend to depreciate in value when they are used whereas knowledge appreciates when it is used and depreciates when it is not used (Gottschalk, 2004; Islam, Kunifuji, Miura, \& Hayama, 2011).

Basically, knowledge can be classified into two types which are explicit knowledge and tacit knowledge (Nonaka, 1994; Polanyi, 1966). According to Nonaka and Takeuchi (1995), explicit knowledge can be transmitted formally and systematically. It is also reusable and readily communicated and shared through print, electronic methods and the like. The most common forms of explicit knowledge are reports, manuals, patents, videos, audiotapes, and databases (Takeuchi \& Nonaka, 2004). In contrast, tacit knowledge is more difficult to formalise and communicate to others (Goh, 2002) as it resides within the human minds (Al-Hawamdeh, 2002). Tacit knowledge is more complex and it needs time and personal insights in order for a person to gain the knowledge (Goh, 2002). Tacit knowledge is not easily articulated (Davenport \& Prusak, 1998) and disseminated (Mullins, 2005). As discovered by Von Nordenflycht (2010), tacit knowledge is difficult to transfer, because it needs to be experienced in order to be fully understandable. In contrast, the explicit knowledge is stored in an organisation's information system, trust and co-operation are needed in support of effective explicit knowledge transfer.

Nonaka and Takeuchi (1995) describe how knowledge can be transferred. Socialisation is a process of creating new tacit knowledge via sharing whereas externalisation is a process of transforming tacit knowledge into explicit knowledge. Combination is a process of exchanging and combining of explicit knowledge held by individuals, while, internalisation is achieved when individuals gained tacit knowledge from learning explicit knowledge (Nonaka \& Takeuchi, 1995). 


\subsection{Network characteristics $(N C)$}

In this study, the researchers examine network characteristics based on the strength of the relationships. Basically, network can be divided into strong tie and weak tie networks (Kozan \& Akdeniz, 2014). Individuals in the strong tie mostly know each other very well such as family members and close friends whereas individuals in the weak tie are not closely related, for example, employees working in the same organisation but in different branches, who have irregular contact. Easley and Kleinberg (2010) found that it is easier to form and accumulate links (followers or friends) in social media sites with the formation of weak ties compared to strong ties. Employees needs to continuously invest time and effort in maintaining strong tie networks in the organisation while, weak tie networks can be established at the beginning stage but not necessarily maintained continuously (Chen, 2009; Easley \& Kleinberg, 2010).

According to Granovetter (1973), employees connected through weak ties are more likely from different social circles and with diverse perspectives. Weak ties enable different ideas and sources to be garnered by the decision maker from diverse networks (Kyriakidou \& Èzbilgin, 2006). On the other hand, Krackhardt (1992) argued that the strong tie is useful when a major change is needed, such as establishing a new business. Besides that, strong tie also plays an essential role in providing access to the sensitive information that requires trustworthiness.

Network characteristics among employees in a corporation with international business associates can facilitate knowledge transfer and improve the quality of information received (Chen, 2009; Cross \& Cummings, 2004). According to Whittaker, Burns, and Van Beveren (2003), strong ties among employees are useful for acquiring knowledge as well as for transferring knowledge across border. Reagans and McEvily (2003) revealed that the effectiveness of knowledge transfer can be influenced by the tie network characteristics. The stronger the tie between knowledge source and knowledge recipient, the more frequent knowledge can be transferred across border.

\subsection{Knowledge context (CT)}

The discussion of knowledge context can be seen commonly from the researches on information systems such as how systems react and provide adequate services to the users based on different contexts, which is also known as context-awareness (Hong, Suh, Kim, \& Kim, 2009; Jiang et al., 2010). According to Pomerol and Brezillon (2001), knowledge context can be defined as conditions that make a situation unique so that employees can apply their "know how" in decision making. However, there is limited research study on the effects of knowledge context on the effectiveness of cross-border knowledge transfer. Most of the past researches merely studied on the relationship between knowledge context and network's formation (Burger \& Buskens, 2009; Fazeen, Dantu, \& Guturu, 2011; McPherson, Smith-Lovin, \& Cook, 2001; Slaughter, Yu, \& Koehly, 2009). Easley and Kleinberg (2010) argued that a knowledge network's formation can be affected by the surrounding contexts. Homophily is one of the surrounding contexts that explains how people choose to be friends (forming a network) based on the similarity of knowledge source and recipient, such as location, race, gender and etc., of each other (Yuan \& Gay, 2006). Since different knowledge contexts lead to different decisions, it can be assumed that the decision in choosing the types of knowledge (tacit and explicit) could be affected by the context. Hence, this study will also examine the relationship between context and network characteristics which might indirectly affect the effectiveness of cross-border knowledge transfer. 
Apart from these, this study will also test the relationships between knowledge characteristics and network characteristics as past researchers has never considered these two characteristics jointly. A total of five hypotheses have been formulated as below (refer to Fig. 1):

H1: There is a positive relationship between knowledge characteristics and the effectiveness of knowledge transfer

H2: There is a positive relationship between knowledge context and the effectiveness of knowledge transfer

H3: There is a positive relationship between network characteristics and the effectiveness of knowledge transfer

H4: There is a correlation between context and knowledge characteristics

H5: There is a correlation between context and network characteristics

H6: There is a correlation between knowledge characteristics and network characteristics

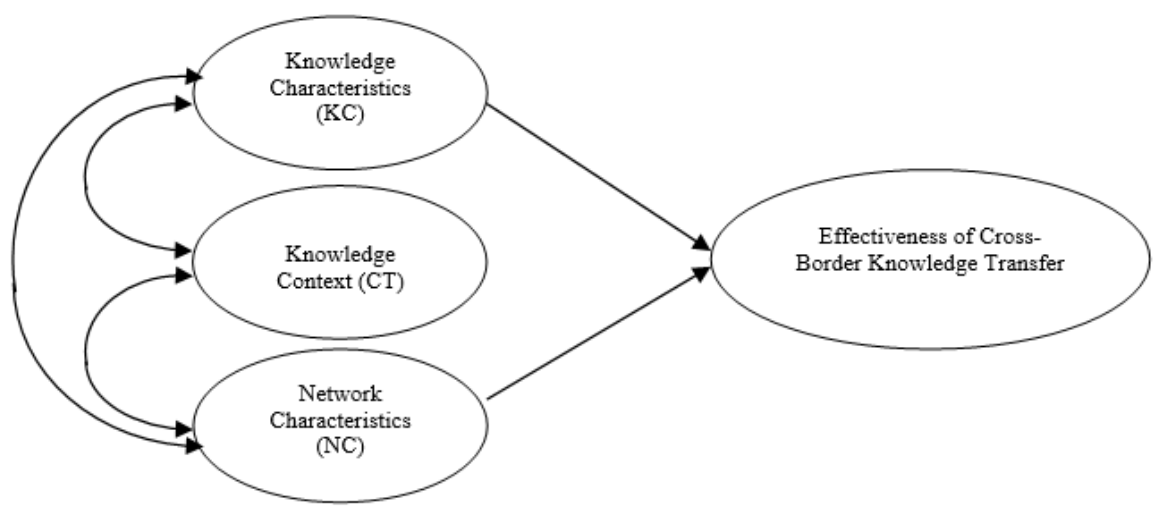

Fig. 1. Proposed research framework

\section{Methodology}

The purpose of this study is to examine the influences of knowledge characteristics and network characteristics on cross-border knowledge transfer in the context of MSC status corporations in Malaysia. Fig. 1 is the proposed framework. In this study, organisation has been viewed as unit of analysis. As this study employed quantitative approach, a survey was designed and distributed to a sample of 300 respondents; however, only 152 were obtained. According to Hair, Anderson, Tatham, and Black (1995), minimum sample size for achieving adequate statistical power for data analysis in Structural Equation Modeling (SEM) is 100. Furthermore, Hair, Babin, Money, and Samouel (2003) also suggested that the minimum sample size to ensure the stable of Maximum likelihood estimation (MLE) is $100-150$. Apparently, this study has met the minimum sample size requirement.

The 3 independent constructs (knowledge, network and context characteristics) and 1 dependent variable (effectiveness of cross-border knowledge transfer) were assessed using Likert Five-point interval scales. The respondents are expected to express their level of agreement or disagreement to each given question on a scale of 1 to 5 (i.e. 1 
= strongly disagree, $2=$ disagree, $3=$ not sure, $4=$ agree, and $5=$ strongly agree). In this study, all the questions of the instrument were adapted from the literature. Based on Cummings and Teng (2003) and Evangelista (2009), four items, which are embeddedness, articulateness, acquired explicit know-how and acquired tacit know-how, can be used to measure $\mathrm{KC}$. On the other hand, to measure $\mathrm{NC}$, social interaction was adapted from the study conducted by Ngoc (2005). For CT, this study adapted the items such as organisational culture, trust and leadership style designed by Jalal (2012), Santoro and Gopalakrishnan (2000) and Ngoc (2005). According to Pérez-Nordtvedt et al. (2008), the effectiveness of knowledge transfer can be measured based on four items, which are comprehension, usefulness, speed and economy.

The targeted respondents of this research are MSC status corporations in Malaysia that involve in any business/industry with international affiliation/activities. Malaysia Digital Economy Corporation (MDEC) which directs and oversees Malaysia's National ICT initiative had been approached to assist in selecting the $300 \mathrm{MSC}$ status corporations (purposive sampling). Representative from senior management (one representative from one corporation) who has direct involvement in international activities was requested to answer the questionnaire. Respondents from Malaysian MSC status corporations are treated as recipients and their international business affiliates (IBA) as sources. IBA can be referred as organisations located outside Malaysia with which the recipient firm has a relationship. The affiliates could be both external entities (foreign suppliers, customers, alliance partners) and internally connected entities (foreign subsidiaries). In this study, Statistical Package for the Social Sciences (SPSS) statistical software version 19 was used to analyse the descriptive statistics, while Analysis of Moment Structures (AMOS) 21 was used to run SEM.

\section{Findings}

Table 1 shows the results of frequency analysis based on the demographic backgrounds of the respondents (representatives of MSC status corporations). The result shows that the number of male respondents $(50 \%)$ is equal to female respondents $(50 \%)$ and majority of the respondents are 21 to 30 years old $(46.7 \%)$, followed by 31 to 40 years old $(36.2 \%)$. The number of respondents who received knowledge from their externally connected entities (inter-organisational relationship), such as foreign customers, suppliers and strategic alliance partners, $(61.8 \%)$ is more than those who received knowledge from their internally connected entities (intra-organisational relationship), such as foreign subsidiaries $(38.2 \%)$. Furthermore, many respondents answered "Neutral" $(44.1 \%)$, followed by "Infrequent" $(21.7 \%)$ in the question of "Knowledge Transfer Involvement" In addition, majority of the respondents come from corporations which have established for more than 10 years (92\%) with the not more than 100 employees (46\%). The results of reliability analysis, normality assessment, regression analysis, and correlation based on SEM analysis will be presented in the following section.

Table 1

The respondents' profile

\begin{tabular}{lll}
\hline Variable & Frequency & Percentage \\
\hline Sex & 76 & $50 \%$ \\
Male & 76 & $50 \%$ \\
Female & & \\
Age & &
\end{tabular}




$$
\begin{aligned}
& <21 \\
& 21-30 \\
& 31-40 \\
& 41-50 \\
& 51-60 \\
& >61
\end{aligned}
$$

\section{Types of IBA Relationship}

Inter-organisational relationship

Intra-organisational relationship

Years of Company Establishment

$$
<5
$$

$5-10$

$>10$

Knowledge Transfer Involvement

Very infrequent

Infrequent

Neutral

Frequent

Very frequent

Number of Employees in the

\section{Organisation}

$$
<100
$$

$100-200$

$201-300$

$301-400$

$401-500$

$>500$

\section{4}

71

55

15

4

3

94

58

$61.8 \%$

$38.2 \%$

$15.8 \%$

$23.7 \%$

$60.5 \%$

36
92

$12.5 \%$

19

$21.7 \%$

$44.1 \%$

$14.5 \%$

22

11

$7.2 \%$

$30.3 \%$

$22.4 \%$

$15.8 \%$

$7.2 \%$

$2.6 \%$

$21.7 \%$

Table 2 shows the Cronbach's alpha for each variable. Based on Table 2, Cronbach's alpha value of all the variables are above 0.7 , which is considered internally consistent. Kline (1998) suggested that the reliability coefficients around 0.9 can be considered "excellent", values around 0.8 as "very good", values around 0.7 as "adequate", and those below 0.5 should be avoided. Examples of the questions which adapted from the literature will be provided in Appendix I.

Table 2

Cronbach's alpha

\begin{tabular}{lcc}
\hline Variable & Number of Items & Cronbach's Alpha \\
\hline Knowledge Characteristics & 16 & 0.830 \\
Knowledge Context & 16 & 0.833 \\
Network Characteristics & 4 & 0.723 \\
Knowledge Transfer & 14 & 0.869 \\
\hline
\end{tabular}


In order to achieve normality, the benchmark \pm 1.0 can be used in measuring the value of skewness (Coakes \& Steed, 2009) whereas the benchmark \pm 3.0 can be used in measuring the value of kurtosis (Balanda \& MacGillivray, 1988). Table 3 shows the results of normality assumption. Based on the results, all items have met the requirements of normality. The final structural model of this study is in Fig. 2.

Table 3

Results of normality assessment

\begin{tabular}{|c|c|c|c|c|c|c|}
\hline Variable & $\min$ & $\max$ & $\overline{\text { skew }}$ & c.r. & kurtosis & c.r. \\
\hline speed03 & 1.000 & 5.000 & -.397 & -1.999 & .227 & .572 \\
\hline speed02 & 1.000 & 5.000 & -.306 & -1.541 & .108 & .273 \\
\hline speed01 & 1.000 & 5.000 & -.682 & -3.431 & .348 & .876 \\
\hline useful03 & 1.000 & 5.000 & -.228 & -1.147 & .794 & 1.998 \\
\hline useful02 & 1.000 & 5.000 & -.290 & -1.462 & .665 & 1.675 \\
\hline context03 & 1.000 & 5.000 & -.056 & -.281 & .265 & .667 \\
\hline context02 & 1.000 & 5.000 & .034 & .173 & .374 & .942 \\
\hline network04 & 1.000 & 5.000 & -.503 & -2.534 & 1.075 & 2.706 \\
\hline network03 & 1.000 & 5.000 & .092 & .465 & .656 & 1.652 \\
\hline network01 & 1.000 & 5.000 & -.257 & -1.294 & 1.035 & 2.605 \\
\hline tacit04 & 1.000 & 5.000 & .169 & .852 & .026 & .065 \\
\hline tacit03 & 1.000 & 5.000 & -.038 & -.189 & .359 & .905 \\
\hline tacit01 & 1.000 & 5.000 & -.425 & -2.138 & .372 & .936 \\
\hline explicit03 & 1.000 & 5.000 & .312 & 1.572 & 1.127 & 2.835 \\
\hline explicit01 & 1.000 & 5.000 & .289 & 1.457 & .729 & 1.835 \\
\hline embedded02 & 2.000 & 5.000 & .544 & 2.740 & .842 & 2.119 \\
\hline embedded01 & 1.000 & 5.000 & -.313 & -1.575 & 1.375 & 3.459 \\
\hline Multivariate & & & & & 160.508 & 38.929 \\
\hline
\end{tabular}

As depicted in Table 4, the structural model of this study fulfils the acceptable requirement of the goodness of fit indices such as the chi-squared per degree of freedom (Chisq/df) of less than or equal to 5.0 (Bollen, 1989), comparative fit index (CFI) of greater than or equal to 0.9 (Hu \& Bentler, 1999), increment fit index (IFI) of greater than or equal to 0.9 (Hu \& Bentler, 1999), Tucker-Lewis index (TLI) of greater than or equal to 0.9 (Bentler \& Bonett, 1980) and root mean squared error of approximation (RMSEA) of less than or equal to 0.08 (Steiger, 1990), indicating that the model is structural fit to explain variance in the effectiveness of cross-border knowledge transfer. 


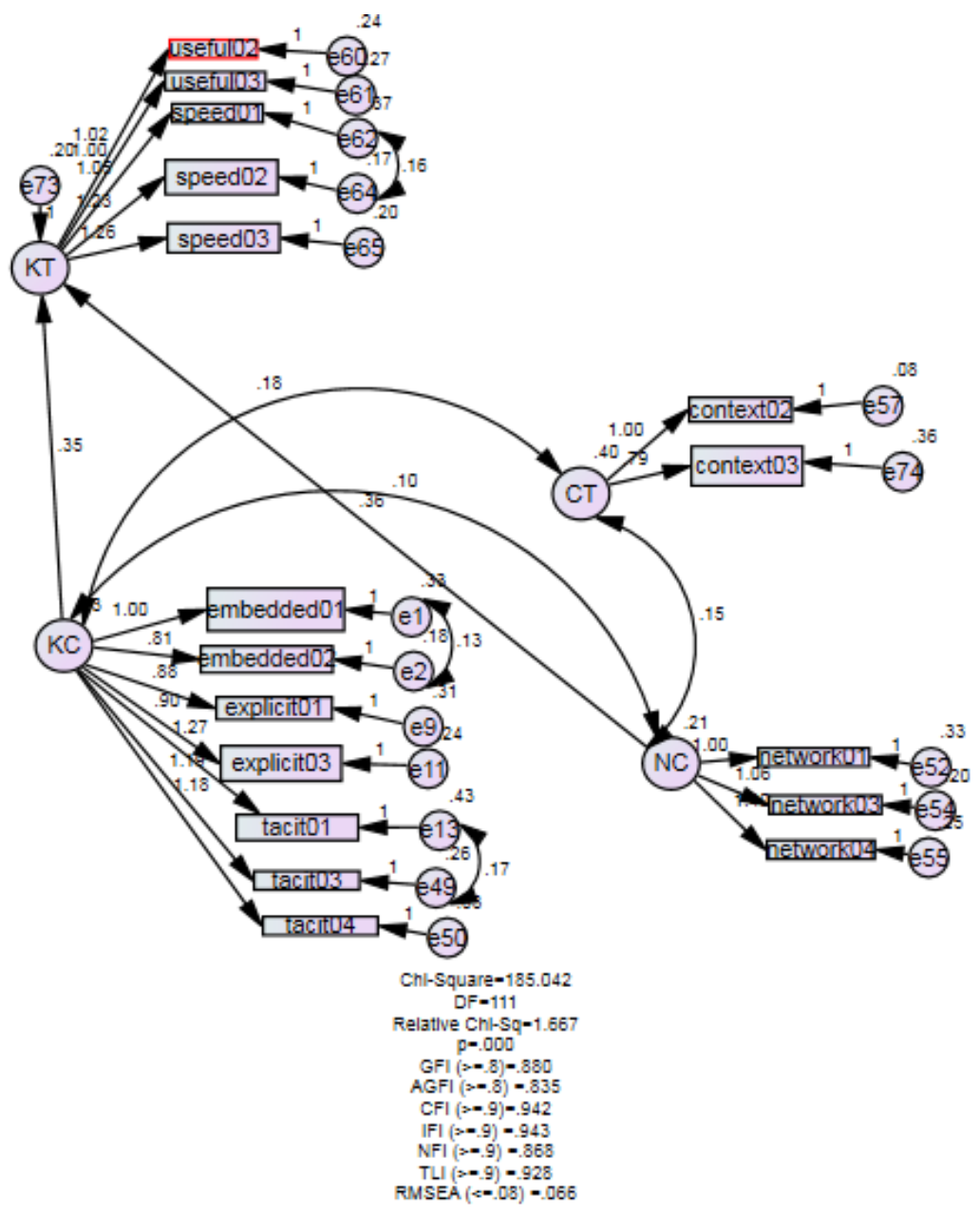

Fig. 2. The structural model

Table 4

Fitness indexes of the structural model

\begin{tabular}{ll}
\hline Name of Index & Index value \\
\hline Chisq $/$ df $(\leq 5.0)$ & 1.667 \\
CFI $(\geq 0.9)$ & .942 \\
IFI $(\geq 0.9)$ & .943 \\
TLI $(\geq 0.9)$ & .928 \\
RMSEA $(\leq 0.08)$ & .066 \\
\hline
\end{tabular}

To accept the hypotheses, the significance value (p) must be less than 0.05 . Table 5 (Regression Analysis) shows the hypotheses testing results for the causal effects of $\mathrm{KC}$ and NC on KT. Thus, H1, H3 were supported and accepted while H2 is not supported. 
Table 5

Results of regression analysis

\begin{tabular}{llllc}
\hline & & $\begin{array}{l}\text { Unstd. } \\
\text { Estimate }\end{array}$ & Std. Estimate & $p$ \\
\hline $\begin{array}{l}\text { Knowledge } \\
\text { Transfer (KT) }\end{array}$ & $<---\begin{array}{l}\text { Knowledge } \\
\text { Characteristics } \\
(\text { KC) }\end{array}$ & .350 & .315 & .003 \\
$\begin{array}{l}\text { Knowledge } \\
\text { Transfer (KT) }\end{array}$ & $\begin{array}{l}\text { Network } \\
\text { Characteristics } \\
\text { (NC) }\end{array}$ & .362 & .310 & .005 \\
\hline
\end{tabular}

Note. ${ }^{* * * I n d i c a t e s ~ h i g h l y ~ s i g n i f i c a n t ~ a t ~ t h e ~} 0.001$ level (two-tailed)

Table 6 shows the hypotheses testing results for the correlations among KC, NC and $\mathrm{CT}$. The results revealed that $\mathrm{KC}, \mathrm{NC}$ and $\mathrm{CT}$ were significantly correlated with each other. Thus, H4, H5 and H6 were supported.

Table 6

Results of correlations

\begin{tabular}{|c|c|c|c|}
\hline & & Estimate & $\mathbf{P}$ \\
\hline $\begin{array}{l}\text { Knowledge } \\
\text { Characteristics <--> } \\
(\mathrm{KT})\end{array}$ & $\begin{array}{l}\text { Knowledge Context } \\
\text { (CT) }\end{array}$ & .601 & $* * *$ \\
\hline $\begin{array}{l}\text { Network } \\
\text { Characteristics <--> } \\
\text { (NC) }\end{array}$ & $\begin{array}{l}\text { Knowledge Context } \\
\text { (CT) }\end{array}$ & .523 & $* * *$ \\
\hline $\begin{array}{l}\text { Knowledge } \\
\text { Characteristics <--> } \\
(\mathrm{KT})\end{array}$ & $\begin{array}{l}\text { Network } \\
\text { Characteristics (NC) }\end{array}$ & .443 & $* * *$ \\
\hline
\end{tabular}

\section{Discussion}

This study employed the SEM approach to test and prove the significant impacts of KC and $\mathrm{NC}$ on $\mathrm{KT}$ in the context of MSC status corporations in Malaysia. The following discussion is based on the findings of this study. Table 7 is the summary of the findings related to each hypothesis.

The results of this SEM found positive significant relationship between $\mathrm{KC}$ and $\mathrm{KT}$, and between $\mathrm{NC}$ and $\mathrm{KT}$. This shows that the impacts of $\mathrm{KC}$ and $\mathrm{NC}$ will affect the effectiveness of cross-border knowledge transfer in the respondent corporations in Malaysia. The results are in line with the findings from past researches. There is a significant relationship between $\mathrm{KC}$ and effectiveness of knowledge transfer (Shen, Li, \& Yang, 2015). According to Kogut and Zander (1993), Simonin (1999) and Dhanaraj, Lyles, Steensma, and Tihanyi (2004), codified or explicit knowledge is easier to be transferred compared to tacit knowledge. The more explicit the knowledge is, the easier 
the knowledge can be transferred. Concretely, tacit knowledge is difficult to acquire, comprehend and transfer as it is highly embedded in the context in which it has been produced (Hamel, 1991; Badaracco, 1991; Junni, 2007). Therefore, Kang et al. (2010) suggested to transform tacit knowledge into explicit knowledge before the knowledge being transferred. By doing so, knowledge can be comprehended easily (effectiveness). As highly personal tacit knowledge is hard to formalise, it is best transferred via long term visits, personnel transfers, or personal communications (Inkpen \& Dinur, 1998). This poses specific challenges to transfers in an inter-organisational context. Moreover, the content that is to be transferred, i.e. whether knowledge differs in that it relates to products, markets, or processes, influences decisions on knowledge transfer. The degree of tacitness, and how quickly the body of knowledge is changing, determine which modes of collaboration are most suitable, knowledge transfer effectiveness (Khamseh \& Jolly, 2008) as well as the speed at which knowledge transfer can be carried out (Chen, 2004a). For example, it may be well worthwhile spending time and effort on developing a sophisticated e-learning module if the knowledge is stable over time.

Table 7

Hypotheses results

\begin{tabular}{lc}
\hline Hypotheses & Result \\
\hline H1: There is a positive relationship between knowledge & Supported \\
characteristics and the effectiveness of knowledge transfer & \\
H2: There is a positive relationship between knowledge context and \\
the effectiveness of knowledge transfer & Not supported \\
H3: There is a positive relationship between network characteristics & Supported \\
and the effectiveness of knowledge transfer & \\
H4: There is a correlation between context and knowledge \\
characteristics \\
$\begin{array}{l}\text { H5: There is a correlation between context and network } \\
\text { characteristics }\end{array}$ \\
$\begin{array}{l}\text { H6: There is a correlation between knowledge characteristics and } \\
\text { network characteristics }\end{array}$ \\
\hline
\end{tabular}

On the other hand, the effects of network can also influence the performance of knowledge exchange (Crispeels, Willems, \& Brugman, 2015). Reagans and McEvily (2003) cited that both tacit and explicit knowledge can be transferred easily via a strong tie network. The strong tie networks make information transmission high and create good environments for exploitative learning. Besides that, trust can also be found in strong ties (Carolan \& Natriello, 2005). People are more likely to receive information or other resources from those who they are closed with as they tend to be trusting each other. Also, information is more accessible and people are more willing to help each other in strong ties (Krackhardt, 1992). Therefore, the stronger the network, the easier the knowledge can be transferred. In addition, the findings of this study also revealed that $\mathrm{KC}, \mathrm{NC}$ and CT were significantly correlated with each other. Brachos, Kostopoulos, Soderquist, and Prastacos (2007) found that the level of perceived usefulness of knowledge in a business unit can be affected by the contextual factors such as trust and management support. Ghoshal and Nohria (1989) argue that the headquarters - subsidiary relationship in each contextual category is a correspondingly differentiated combination of the following 
elements: 1) centralisation, the lack of subsidiary autonomy in decision making; 2) formalisation, the use of systematic rules and procedures in decision making; and 3) normative integration, consensus and shared values as a basis for decision-making. Therefore, this study proposes that knowledge transfer is manifested through specific configurations of organisational design characterised by different degrees of autonomy, formalisation, and integration. Ghoshal and Nohria (1989) proposed that centralisation is negatively correlated with local resource levels. Centralisation shifts the locus of power asymmetrically in favour of the headquarters, and formal authority and hierarchical mechanisms used in decision making processes hinder the subsidiaries' knowledge development. Autonomy, as the opposite to centralisation, is expected to be positively related to local resources levels. It gives subsidiaries more freedom and authorisation to create and develop knowledge by themselves, rather than through absorbing knowledge from other subsidiaries or the headquarters. When a subsidiary has more advanced resources in terms of knowledge than other units in an MNC, more knowledge is likely to transfer from this subsidiary to other parts of the MNC (Björkman, Barner-Rasmussen, \& Li, 2004; Wang, Tong, \& Koh, 2004). Therefore, it could be expected that knowledge outflow of subsidiaries is negatively related to centralisation, i.e., positively related to autonomy. To do so, a managerial mechanism needs to be in place to configure interorganisational knowledge transfer. Prior research has shown that the configuration of these characteristics should fit the context in which knowledge is transferred (Hutzschenreuter \& Listner, 2007). For companies with a number of different network partners, those contexts can be highly diverse. In order to achieve the crucial fit between configuration and context, the company might carry out individual transfer projects designed specifically for each partner contingent on their particular characteristics and needs. Since the knowledge transfer is designed specifically to fulfil the exact requirements of each partner, thus to contribute to the partner's business processes, the benefits are usually greater (Chen, 2004b).

In contrast, the company might choose to standardise knowledge transfer to a certain degree, i.e. to configure certain knowledge transfer characteristics in advance. A knowledge transfer product is an offering to transfer certain knowledge over a predefined channel. In the case of standardised knowledge transfer products, such as new product information that is taught in classroom training, text books, course material, or cases, particular knowledge and transfer characteristics are fixed without knowing the exact transfer context. Standardised delivery can be carried out at lower cost as the company can make savings both in knowledge transfer planning and implementation (Levin \& Cross, 2004). The downside is that standardised knowledge transfer neglects differences in the context, e.g. in the situation of partners and in the value they create for the company. The challenge for company managers in large networks is to strike a balance between potential savings on the side of standardisation against the value knowledge transfer can create for the company, value that could be augmented by individualised training. Managing the configuration of knowledge transfer can be done in the form of a programme. A knowledge transfer programme predetermines a set of rules according to which knowledge transfer is configured for all partners enrolled in that programme. Based on specific characteristics, like partner size, these rules may specify how knowledge transfer is configured, in an entirely individualised or partly standardised way. If these rules are known to partners, they also know what knowledge transfer they will receive before joining the programme. Programme rules also may define dependencies between knowledge transfer characteristics. For example, whether particular knowledge content is offered to partners may be dependent on certain partner characteristics, like the present duration of the partnership. 


\section{Recommendations}

This study provides evidence that $\mathrm{KT}$ is affected by $\mathrm{KC}$ and $\mathrm{NC}$, which is beneficial for Malaysian MSC status corporations. The managers of MSC status corporations can use this study as a general guideline in implementing cross-border knowledge transfer. Based on the findings, the easier the knowledge can be interpreted and understood, the more effective the knowledge transfer can be achieved. Hence, if possible, Malaysian MSC status corporations should encourage their IBAs, regardless based on inter- or intraorganisational relationship, to put more efforts in codifying knowledge. Besides that, they should also develop a strong tie network, such as joint venture, with their IBAs in order to improve the performance of knowledge transfer. By doing this, trust can be developed and the process of transferring knowledge, especially tacit knowledge, will become easier. Additionally, contexts such as where (right place), how (right instrument) and when (right time), should be focused while transforming knowledge or forming a network. For knowledge sharing initiatives to be effective, they need to be introduced by senior and middle managers whom not only understand and support the strategic and operational need to align business and KM strategy but also recognise the human, organisational, and technological challenges of newly introduced actions. In particular, it seems important that senior and middle managers know how to overcome diverse barriers by encouraging and motivating people in the internal and external value chain to share their knowledge more openly. Competitive advantages are determined in various ways, by: people (e.g. software, law, and accounting firms), structure and internal processes (e.g. mining and agricultural companies), memory systems (e.g. business advisories and consultancies), stakeholder relationships (e.g. manufacturing firms, fashion houses, and government), and/or business environment (e.g. finance and investment firms). Knowledge transfer practices between individual people as well as organisational units often form a key component of KM programs and can create significant short- and long-term operational and learning benefits. Further, there is evidence that organisations that effectively manage and transfer their knowledge are more innovative and perform better. Integrate IT systems and tools suitable to people's way of doing their tasks on a daily basis and communicating with each other (i.e. most information is locked in electronic documents hence any KM solution requires a strong integration). Conduct a needs audit of the existing infrastructure to assess which tools can be built upon and which new ones need to be implemented. Ensure that tools are consistent with the organisation's culture and work styles. Explain to your people, clearly and carefully, how tools are to be used. Hold initial training and familiarisation sessions for newly introduced tools and highlight any potential usability/ technology issues (depending on varying skills levels and needs). Certify people on their ability to navigate tools, if appropriate. Create an open communication flow without restrictions between diverse organisational levels. Establish a "no limits" environment between all existing hierarchies or levels. Encourage direct contact between knowledge sources and recipients to minimise distortion of knowledge or information. Provide methods, systems and tools that encourage and facilitate direct and indirect communication flows. Form small units or project teams to facilitate better direct communication flows and enhance collaboration. Conduct detailed knowledge audit and gap analysis. Implement processes that support the existing culture and work styles. Identify people in need of knowledge and clarify what kind of information and knowledge they need to share, and the infrastructure and resources necessary to provide better sharing. Get senior management to assess financial commitment against sharing benefits. Allocate adequate resources to undertake tasks for which people are given responsibility, and support most effective forms of communication and collaboration. Determine what it really is that motivates people to join and then stay with the firm. Tell people what specific impact their knowledge makes/made and reward them accordingly. 
Ensure that people are placed in positions in which their responsibilities match their skill set and career aspirations, i.e. mismatches only create inefficiencies and people working below their capacities. Involve, where possible and beneficial, retired and former longtime employees in short-term projects or employ them as business advisors, mentors and/or consultants thereby continuing to invest their knowledge into the organisation's further development. Offer internal and external management training and development programs, and ensure succession planning. Provide corporate benefit programs to encourage people's loyalty and on-going commitment to the firm, e.g. award loyalty through either monetary and/or non-monetary incentives. Give exit interviews to both outgoing employees and clients to better determine where they may have experienced problems or challenges, and improve on them.

\section{Conclusion}

In conclusion, this study proposed a research framework for examining the factors that affecting cross-border knowledge transfer in Malaysian MSC status corporations. Two independent variables (KC and $\mathrm{NC}$ ) and one dependent variable (the effectiveness of cross-border knowledge transfer) have been proposed in the research framework of this study. This study found that both independent variables, $\mathrm{KC}$ and $\mathrm{NC}$, have significant positive relationships with the effectiveness of cross-border knowledge transfer; while, $\mathrm{KC}, \mathrm{NC}$ and $\mathrm{CT}$ were significantly correlated with each other. Compared to tacit knowledge, explicit knowledge is easier to be transferred in the global context. Besides that, the stronger the networks tie, the more knowledge will be transferred among the people in the network as they tend to be trusting each other. The findings of this study can be used to propose as a guideline or policy that can enhance the effectiveness of cross-border knowledge transfer in Malaysia. In future research, factor such as media characteristics could be examined and integrated as part of the research framework.

\section{References}

Adams, M., \& Comber, S. (2013). Knowledge transfer for sustainable innovation: A model for academic-industry interaction to improve resource efficiency within SME manufacturers. Journal of Innovation Management in Small \& Medium Enterprise. doi: $10.5171 / 2013.999612$

Al-Hawamdeh, S. (2002). Knowledge management: Re-thinking information management and facing the challenge of managing tacit knowledge. Information research, 8(1): 143.

Albino, V., Garavelli, A. C., \& Gorgoglione, M. (2004). Organization and technology in knowledge transfer. Benchmarking: An International Journal, 11(6), 584-600.

Awang, A. H., Hussain, M. Y., \& Malek, J. A. (2009). Promoting knowledge transfer in science and technology: A case study of Technology Park Malaysia (TPM). Croatian Economic Survey, 11, 95-113.

Badaracco, J. L. (1991). The knowledge link: How firms compete through strategic alliances. Boston: Harvard Business School Press.

Balanda, K. P., \& MacGillivray, H. L. (1988). Kurtosis: A critical review. The American Statistician, 42(2), 111-119.

Bentler, P. M., \& Bonett, D. G. (1980). Significance tests and goodness of fit in the analysis of covariance structures. Psychological Bulletin, 88(3), 588-606.

Björkman, I., Barner-Rasmussen, W., \& Li, L. (2004). Managing knowledge transfer in MNCs: The impact of headquarters control mechanisms. Journal of international 
business studies, 35(5), 443-455.

Bollen, K. A. (1989). Structural equations with latent variables. New York: John Wiley $\&$ Sons.

Brachos, D., Kostopoulos, K., Soderquist, K. E., \& Prastacos, G. (2007). Knowledge effectiveness, social context and innovation. Journal of knowledge management, 11(5), 31-44.

Burger, M. J., \& Buskens, V. (2009). Social context and network formation: An experimental study. Social Networks, 31(1), 63-75.

Carlile, P. R., \& Rebentisch, E. S. (2003). Into the black box: The knowledge transformation cycle. Management science, 49(9), 1180-1195.

Carolan, B., \& Natriello, G. (2005). Strong ties, weak ties: Relational dimensions of learning settings. Paper presented at the Annual Meeting of the American Educational Research Association.

Cavusgil, S. T., Calantone, R. J., \& Zhao, Y. (2003). Tacit knowledge transfer and firm innovation capability. Journal of Business \& Industrial Marketing, 18(1), 6-21.

Chen, C. J. (2004a). The effects of knowledge attribute, alliance characteristics, and absorptive capacity on knowledge transfer performance. R\&D Management, 34(3), 311-321.

Chen, C. J. (2004b). The determinants of knowledge transfer through strategic alliances. Academy of Management Proceedings. doi: 10.5465/AMBPP.2004.13857556

Chen, I. Y. L. (2009). Social capital, IT capability, and the success of knowledge management systems. Knowledge Management \& E-Learning, 1(1), 36-50.

Chen, W. L., Sandhu, M. S., \& Jain, K. K. (2009). Knowledge sharing in an American multinational company based in Malaysia. Journal of Workplace Learning, 21(2), $125-142$.

Chong, C. W., Chong, S. C., \& Gan, G. C. (2011). Inter-organizational knowledge transfer needs among small and medium enterprises. Library Review, 60(1), 37-52.

Ciabuschi, F., Martín, O. M., \& Ståhl, B. (2010). Headquarters' influence on knowledge transfer performance. Management International Review, 50(4), 471-491.

Coakes, S. J., \& Steed, L. (2009). SPSS: Analysis without anguish using SPSS version 14.0 for Windows. Brisbane: John Wiley \& Sons.

Crispeels, T., Willems, J., \& Brugman, P. (2015). The relationship between organizational characteristics and membership of a biotechnology industry board-ofdirectors-network. Journal of Business \& Industrial Marketing, 30(3/4), 312-323.

Cross, R., \& Cummings, J. N. (2004). Tie and network correlates of individual performance in knowledge-intensive work. Academy of Management Journal, 47(6), 928-937.

Cummings, J. L., \& Teng, B. S. (2003). Transferring R\&D knowledge: The key factors affecting knowledge transfer success. Journal of Engineering and Technology Management, 20(1/2), 39-68.

Davenport, T. H., \& Prusak, L. (1998). Working knowledge: How organizations manage what they know. Boston: Harvard Business School Press.

Dhanaraj, C., Lyles, M. A., Steensma, H. K., \& Tihanyi, L. (2004). Managing tacit and explicit knowledge transfer in IJVs: The role of relational embeddedness and the impact on performance. Journal of International Business Studies, 35(5), 428-442.

Easley, D., \& Kleinberg, J. (2010). Networks, crowds, and markets: Reasoning about a highly connected world (pp. 77-106). Cambridge UK: Cambridge University Press.

Evangelista, F. (2009). Organisational context and knowledge acquisition in IJVs: An empirical study. Journal of World Business, 44(1), 63-73.

Fallah, M. H., \& Ibrahim, S. (2004, April). Knowledge spillover and innovation in technological clusters. In Proceedings of the IAMOT Conference (pp. 1-16). 
Fazeen, M., Dantu, R., \& Guturu, P. (2011). Identification of leaders, lurkers, associates and spammers in a social network: Context-dependent and context-independent approaches. Social Network Analysis and Mining, 1(3), 241-254.

Ghoshal, S., \& Nohria, N. (1989). Internal differentiation within multinational corporations. Strategic Management Journal, 10(4), 323-337.

Godbout, A. J., \& Godbout, G. M. (1999). Filtering knowledge: Changing information into knowledge assets. Journal of Systemic Knowledge Management, 1: 11.

Goh, S. C. (2002). Managing effective knowledge transfer: An integrative framework and some practice implications. Journal of Knowledge Management, 6(1), 23-30.

Gottschalk, P. (2004). Strategic knowledge management technology. Hershey, PA: Idea Group Publishing.

Granovetter, M. S. (1973). The strength of weak ties. American Journal of Sociology, $78(6), 1360-1380$.

Hair, J., Anderson, R., Tatham, R., \& Black, W. (1995). Multivariate data analysis: A global perspective (4th ed.). Upper Saddle River, NJ: Prentice Hall.

Hair, Jr, J. F., Babin, B., Money, A. H., \& Samouel, P. (2003). Essentials of business research methods. Hoboken, NJ: Wiley.

Hamel, G., (1991). Competition for competence and interpartner learning within international strategic alliances. Strategic Management Journal 12, 83-103.

Hamid, N. A. A., \& Salim, J. (2011). A conceptual framework of knowledge transfer in Malaysia e-government IT outsourcing: An integration with transactive memory system (TMS). IJCSI International Journal of Computer Science Issues, 8(5), 51-64.

Hong, J., Suh, E. H., Kim, J., \& Kim, S. Y. (2009). Context-aware system for proactive personalized service based on context history. Expert Systems with Applications, 36(4), 7448-7457.

Hu, L., \& Bentler, P. M. (1999). Cutoff criteria for fit indexes in covariance structure analysis: conventional criteria versus new alternatives. Structural Equation Modeling: A Multidisciplinary Journal, 6(1), 1-55.

Hutzschenreuter, T., \& Listner, F. (2007). A contingency view on knowledge transfer: Empirical evidence from the software industry. Knowledge Management Research \& Practice, 5(2), 136-150.

Inkpen, A. C., \& Dinur, A. (1998). Knowledge management processes and international joint ventures. Organization science, 9(4), 454-468.

Inkpen, A. C., \& Tsang, E. W. K. (2005). Social capital, networks, and knowledge transfer. Academy of Management Review, 30(1), 146-165.

Islam, M. S., Kunifuji, S., Miura, M., \& Hayama, T. (2011). Adopting knowledge management in an e-learning system: Insights and views of KM and EL research scholars. Knowledge Management \& E-Learning (KM\&EL), 3(3), 375-398.

Jalal, H. A. (2012). Exploring employees' perceptions of their capability and success of sharing knowledge: Implications for human resource management (HRM). Doctoral dissertation, Massey University, New Zealand.

Jiang, Y., Tang, Y., Wang, J., \& Tang, S. (2010). Representation and reasoning of context-dependant knowledge in distributed fuzzy ontologies. Expert Systems with Applications, 37(8), 6052-6060.

Joshi, K. D., Sarker, S., \& Sarker, S. (2007). Knowledge transfer within information systems development teams: Examining the role of knowledge source attributes. Decision Support Systems, 43(2), 322-335.

Junni, P. (2007). Knowledge transfer in mergers and acquisitions-the roles of fear of exploitation and contamination. Paper presented at the 23rd EGOS Colloquium (Standing Work Group 2: Organizational Network Research). Vienna.

Kang, J., Rhee, M., \& Kang, K. H. (2010). Revisiting knowledge transfer: Effects of knowledge characteristics on organizational effort for knowledge transfer. Expert 
Systems with Applications, 37(12), 8155-8160.

Khamseh, H. M., \& Jolly, D. R. (2008). Knowledge transfer in alliances: Determinant factors. Journal of Knowledge Management, 12(1), 37-50.

Kline, R. B. (1998). Principles and practice of structural equation modelling. New York: Guilford,

Kogut, B., \& Zander, U. (1993). Knowledge of the firm and the evolutionary theory of the multinational corporation. Journal of International Business Studies, 24(4), 625645.

Kozan, M. K., \& Akdeniz, L. (2014). Role of strong versus weak networks in small business growth in an emerging economy. Administrative Sciences, 4(1), 35-50.

Krackhardt, D. (1992). The strength of strong ties: The importance of philos in organizations. In N. Nohria \& R. G. Eccles (Eds.), Networks and Organizations: Structure, Form and Action. Boston: Harvard Business School Press.

Kumar, N., Rose, R. C., \& Muien, N. F. A. (2011). The influences of absorptive capacity and social capital on knowledge transfer. Journal of Applied Business Research (JABR), 25(4): 10.

Kyriakidou, O., \& Ėzbilgin, M. (Eds.). (2006). Relational perspectives in organizational studies: A research companion. Cheltenham, UK: Edward Elgar.

Lee, M. T., Mohayiddin, M. G., \& Kanesan, M. (2011). Soft technology transfer for Japanese MNCs in Malaysia: A conceptual model. In Proceedings of the International Lifelong Learning Conference (ICLLL). Kuala Lumpur.

Levin, D. Z., \& Cross, R. (2004). The strength of weak ties you can trust: The mediating role of trust in effective knowledge transfer. Management Science, 50(11), 1477-1490.

McPherson, M., Smith-Lovin, L., \& Cook, J. M. (2001). Birds of a feather: Homophily in social networks. Annual Review of Sociology, 27, 415-444.

Mullins, L. J. (2005). Management and organizational behaviour (7th ed.). London: Prentice Hall.

Ngoc, P. T. B. (2005). An empirical study of knowledge transfer within vietnam's IT companies. $\quad$ Retrieved from https://pdfs.semanticscholar.org/e08d/da9cb0559133a04f7339c1dc7cab43a903d4.pdf

Nonaka, I. (1994). A dynamic theory of organizational knowledge creation. Organization Science, 5(1), 14-37.

Nonaka, I., \& Takeuchi, H. (1995). The knowledge-creating company: How Japanese companies create the dynamics of innovation. New York: Oxford University Press.

Pérez-Nordtvedt, L., Kedia, B. L., Datta, D. K., \& Rasheed, A. A. (2008). Effectiveness and efficiency of cross-border knowledge transfer: An empirical examination. Journal of Management Studies, 45(4), 714-744.

Pomerol, J. C., \& Brezillon, P. (2001). About some relationships between knowledge and context. Lecture Notes in Computer Science, 2116, 461-464.

Polanyi, M. (1966). The tacit dimension. Garden City, NY: Doubleday Press.

Razak, N. A., Rashid, W. E. W., Ma'amor, H., Asnawi, N. H., Ahmad, N. L., \& Achim, N. A. (2013). Leveraging knowledge transfer in strategic human resource management. International Journal of Trade, Economics and Finance, 4(4), 168-172.

Reagans, R., \& McEvily, B. (2003). Network structure and knowledge transfer: The effects of cohesion and range. Administrative Science Quarterly, 48(2), 240-267.

Santoro, M. D., \& Gopalakrishnan, S. (2000). The institutionalization of knowledge transfer activities within industry-university collaborative ventures. Journal of Engineering and Technology Management, 17(3/4), 299-319.

Sarif, S. M., \& Ismail, Y. (2006). Technology parks, knowledge transfer and innovation: the case of Malaysia's information and communication technology (ICT) small and medium enterprises. International Journal of the Information Systems for Logistics 
and Management, 1(2), 133-142.

Shen, H., Li, Z., \& Yang, X. (2015). Processes, characteristics, and effectiveness: An integrative framework for successful knowledge transfer within organizations. Journal of Organizational Change Management, 28(3), 486-503.

Simonin, B. L. (1999). Ambiguity and the process of knowledge transfer in strategic alliances. Strategic Management Journal, 20(7), 595-623.

Simonin, B. L. (2004). An empirical investigation of the process of knowledge transfer in international strategic alliances. Journal of International Business Studies, 35(5), 407-427.

Slaughter, A. J., Yu, J., \& Koehly, L. M. (2009). Social network analysis: Understanding the role of context in small groups and organizations. In E. Salas, G. F. Goodwin \& C. S. Burke (Eds.), Team Effectiveness in Complex Organizations: Cross-disciplinary Perspectives and Approaches. New York, NY: Routledge.

Steiger, J. H. (1990). Structural model evaluation and modification: An interval estimation approach. Multivariate behavioral research, 25(2), 173-180.

Szulanski, G. (1996). Exploring internal stickiness: Impediments to the transfer of best practice within the firm. Strategic Management Journal, 17(S2), 27-43.

Takeuchi, H., \& Nonaka, I. (Eds.). (2004). Hitotsubashi on knowledge management. Singapore: John Wiley \& Sons.

Tsai, W. (2001). Knowledge transfer in intraorganizational networks: Effects of network position and absorptive capacity on business unit innovation and performance. Academy of Management Journal, 44(5), 996-1004.

Tuomi, I. (1999). Data is more than knowledge: Implications of the reversed knowledge hierarchy for knowledge management and organizational memory. In Proceedings of the 32nd Annual Hawaii International Conference on System Sciences.

Von Nordenflycht, A. (2010). What is a professional service firm? Toward a theory and taxonomy of knowledge-intensive firms. Academy of Management Review, 35(1), $155-174$.

Wang, P., Tong, T. W., \& Koh, C. P. (2004). An integrated model of knowledge transfer from MNC parent to China subsidiary. Journal of World Business, 39(2), 168-182.

Weidenfeld, A., Williams, A. M., \& Butler, R. W. (2010). Knowledge transfer and innovation among attractions. Annals of Tourism Research, 37(3), 604-626.

Whah, C. Y., \& Tiek, L. K. (2013). Networking and knowledge transfer in Malaysian SMEs through university. The Copenhagen Journal of Asian Studies, 30(1), 96-116.

Whittaker, J., Burns, M., \& Van Beveren, J. (2003). Understanding and measuring the effect of social capital on knowledge transfer within clusters of small-medium enterprises. In Proceedings of the 16th Annual Conference of Small Enterprise Association of Australia and New Zealand. Ballarat, Australia.

Yuan, Y. C., \& Gay, G. (2006). Homophily of network ties and bonding and bridging social capital in computer-mediated distributed teams. Journal of Computer-Mediated Communication, 11(4), 1062-1084.

Zarrinmehr, E., \& Rozan, Z. M. A. (2012). Influential factors for knowledge transfer in information system outsourcing. In Proceedings of the Asia-Pacific Business Research Conference. Kuala Lumpur, Malaysia. 


\section{Appendix I}

Questions for each Instruments

\section{Knowledge Characteristics}

Embeddedness

1. Our International Business Affiliate (IBAs) helps us to easily reconfigure and adapt knowledge.

2. Our IBAs helps us to easily learn the tools, equipment and technologies related to this know-how.

3. Our IBAs helps us to easily identify which tools to use to perform each activity, task and procedure.

4. Our IBAs helps us to easily locate and extract the information needed by our company. Articulateness

1. Our employees can easily learn from IBAs by talking to experienced personnel.

2. Educating and training new employees to get involved in cross-border knowledge transfer is a quick and easy job.

3. Cross-border knowledge transfer requires that our employees have long experience in their department to achieve high product quality.

4. Cross-border knowledge transfer requires that our new employees to work with experienced employees from our IBAs as 'apprentices' for a long time to learn their job within important areas.

Acquired Explicit Know-How

1. Read and understand training materials supplied by our IBAs easily.

2. Attend formal lectures conducted by our IBAs regarding different aspects of business frequently.

3. Use manuals prepared by our IBAs to undertake different business activities such as market analysis, pricing, advertising or making a sales presentation.

4. Apply rules and standard operating procedure specified by our IBAs through memos and other written documents in daily business.

Acquired Tacit Know-How

1. Interact closely with our IBAs.

2. Collaborate closely with our IBAs in solving marketing problems or in conducting joint projects (e.g., developing new products or a promotion campaign).

3. Observe how our IBAs solve problems or make decisions.

4. Adopt the rules of thumb or the intuitive approaches used by our IBAs.

\section{Knowledge Context}

1. Our employees use knowledge that they learn from IBAs in different situations, e.g. problems that affect individuals, communities or the whole world.

2. Our employees perform different kinds of knowledge interpretation tasks, such as retrieving specific information, developing an interpretation or reflecting on the knowledge that they obtain from IBAs.

3. Our employees are able to absorb written knowledge for different situations, e.g. for personal interest, or to meet work requirements.

4. Our employees are able to identify evidence, draw, evaluate and communicate conclusions with IBAs.

Organisational Culture

1. Employees are encouraged to suggest ideas for new opportunities.

2. There is a willingness to collaborate across organisations.

3. Employees put much value on taking risk even if that turns out to be a failure.

4. Employees feel confident that the organisation will always try to treat them fairly. Trust

1. Our employees are willing to share ideas, feelings, and specific goals with the IBAs.

2. Our employees understand the IBAs' competence as well as its motives and fairness in sharing these abilities. 
3. Our employees adhere to a set of principles that our IBAs finds acceptable.

4. Information is widely shared so that everyone can get the needed information. Leadership Style

1. Our manager articulates a compelling vision, objectives, and strategies of the future for subordinates to participate in cross-border knowledge transfer.

2. Our manager gets the subordinates to look at problems arising from cross-border knowledge transfer from many different angles.

3. Our manager encourages employees to share knowledge and information with IBAs throughout the company.

4. Our manager demonstrates his cooperative and constructive behaviour when working together with IBAs.

\section{Network Characteristics}

1. Our employees usually take opportunities to discuss with IBAs about work-related issues.

2. Our employees participate in all informal discussion with IBAs

3. Our employees participate in all parties and social activities organized by IBAs.

4. Our employees usually interact with IBAs in person in order to exchange knowledge.

\section{Knowledge Transfer}

Comprehension

The new knowledge that our company acquire is

1. Complete enough that we are able to become proficient with it.

2. Thorough enough that we are able to fully understand it.

3. Well understood in the organisation.

4. Clear enough that we are able to fully understand it.

Usefulness

1. New knowledge transferred from our IBAs contributed a lot to multiple projects

2. Our organisation is very satisfied with the quality of the knowledge that our IBAs provided.

3. Our organisation dramatically increases the perception about the efficacy of the knowledge after gaining experience with it.

4. The transfer of knowledge from the IBAs greatly helps our company in terms of actually improving our organisational capabilities.

1. The rate at which the new knowledge is transferred from our IBAs is very fast.

2. The new knowledge is transferred from our IBAs in a timely fashion.

3. It takes our company a short time to acquire and implement the knowledge provided by our IBAs.

1. The new knowledge provided by our IBAs is acquired and implemented at a very low cost.

2. The acquisition and implementation of the new knowledge from our IBAs do not require the utilisation of too many company resources.

3. Our company does not waste money acquiring and implementing the new knowledge from our IBAs. 